\title{
Review of: "Physico-chemical properties and microbiological status of admixture and single-hive honey produced in Ghana"
}

Jelena Ćirić

Potential competing interests: The author(s) declared that no potential competing interests exist.

Dear authors,

After reading your manuscript, I realized that you were examined Physico-chemical properties and microbiological status of admixture and single-hive honey produced in Ghana. The issue that you dealt with is well described in the paper. Your work complements previous knowledge and opens up the possibility for further research. Paper is technically and clearly written. The claims fully supported the experimental date and discussion is clearly written. The methodological detail and statistical analysis are explain well. Remarks: The linguistic quality of the paper should be revised more carefully once more by English expert.

The Introduction does not indicate the status of current knowledge. Moreover, there doesn't seem to be a clear research hypothesis formulated.

Discussion- There are more and more reports....Insert:

https://www.tandfonline.com/doi/abs/10.1080/03067319.2019.1593972

http://www.journalmeattechnology.com/index.php/meat technology/article/view/2020.61.1.6

https://link.springer.com/article/10.1007/s12011-020-02321-6

https://iopscience.iop.org/article/10.1088/1755-1315/333/1/012050/meta

The experimental design is appropriate to resolve the stated objectives of the study. The experimental techniques are appropriate to resolve the stated objectives of the study.

However, in order to make the Material and Methods more readable, I propose to introduce subchapter, e.g. Sampling (with map of sampling), Analysis, Statistical Analysis, etc.

The discussion is relevant and adequate for full interpretation of results. The results and discussion justify the conclusions drawn from the work.

If the suggested changes and information are correctly clarified, I believe that the manuscript is suitable for publication in Journal. Certainly the results are important to scientific literature. My recommendation is to publish the paper after MAJOR revision of the manuscript.

Sincerely,

Jelena Ćirić, PhD 
